\title{
Derecho de gestión del trabajador: ¿̨realidad o espejismo?
}

\author{
Úrsula Valverde Granados
}

\section{Introducción}

El mayor desarrollo legislativo que tuvo el tema de la participación de los trabajadores en la gestión en el Perú, se registró en los años setenta. Es en este tiempo en que se introduce en el ordenamiento jurídico laboral a la figura de las comunidades laborales (emtes colectivos de participación en la gestión, propiedad y utilidades) técnicamente inspiradas en el modelo yugoeslavo y que constituyeron un ensayo de cogestión de los trabajadores en la empresa.

Desde esa fecha en adelante se constata la tendencia en el ordenamiento jurídico de dar marcha atrás en la regulación del tema, restringiendo cada vez más el derecho de participación del trabajador. Lo que concuerda con el escaso tratamiento de la cuestión por parte de la doctrina. Las razones de lo que bien podría llamarse "animadversión. del sistema son de tipo histórico. Se fundan en el hecho de que la gestió tal y como fue planteada en los setenta no alcanzó sus objetivos, la participación del trabajador nunca fue una realidad, los trabajadores permanecieron indiferentes.

Es justamente esta falta de tratamiento jurídico que hay del tema en nuestro país lo que anima la presente investigación.

Nos hemos planteado analizar desde un punto de vista jurídico la participación en la gestión de los trabajadores, porque hay un gran vacío doctrinal en el Perú sobre esta cuestión y un no menos notorio interés de nuestro legislador en obviar su tratamiento. Situación que no deja de asombrarnos ante la visión de una mayoría de países europeos que regulan la participación en la gestión -si bien en diferentes 
grados y sobre diversas materias- en el nivel de derecho interno e incluso a nivel de derecho comunitario".

Consideramos por ello, que el tema tiene plena vigencia, que el olvido legislativo nacional debe superarse y en ese sentido la presente investigación pretende ser, sobre todo, una propuesta de investigación.

Para el inicio en el análisis de la institución jurídica de la participación en la gestión efectuaremos una primera aproximación al tema, valiéndonos para ello de las opiniones de la doctrina extranjera. Ello nos proporcionará los elementos de juicio necesarios para examinar el régimen jurídico de participación de los trabajadores en la empresa peruana.

Con esta intención, la investigación ha sido dividida en tres capítulos.

El primero pretende proporcionar los conocimientos básicos, indispensables, para el análisis de cualquier sistema de participación en la gestión. Es en este capítulo donde se descubre la naturaleza del derecho de participación en la gestión, como límite al ius variandi del empleador y se recoge la opinión de los autores más reconocidos en la materia, en aspectos claves, como son, el sujeto y objeto del derecho y las peculiaridades de su ejercicio (grados, materias e instrumentos).

El segundo capítulo trata del sistema de participación peruano. Con los conceptos aportados por el capítulo anterior, se intenta un planteamiento general del ordenamiento jurídico peruano sobre participación en la gestión. Se analizan los efectos jurídicos de las disposiciones constitucionales en la materia, y se descubre la incongruencia legislativa al interior del Decreto Legislativo 677, norma que regula la participación en el Perú.

Hecho el diagnóstico preliminar, se presentan posibles soluciones.

Se espera haber cubierto las expectativas generadas con el planteamiento de la investigación, si bien se debe reconocer que es un objetivo muy ambicioso el que nos hemos trazado, no es menos cierto también que las grandes empresas sólo se acaban si se comienzan.

\footnotetext{
* Según lo dispone la Directiva 94/45/CE, de 22 de septiembre de 1994, sobre la constitución de un comité europeo o de un procedimiento de información y consulta a los trabajadores de las empresas comunitarias.
} 


\section{Participación en la gestión}

\subsection{Definición}

\subsubsection{Delimitación del tema}

La doctrina mayoritaria coincide en afirmar que la participación en la gestión no es más que una forma de participación de los trabajadores en la empresa'.

De esta manera los autores diferencian hasta tres formas de participación en la empresa: la participación en las utilidades, en la propiedad y en la gestión. Explica Ermida Uriarte ${ }^{2}$ que ésta es una clasificación del fenómeno de participación en función de su objeto. Por lo que en principio cada tipo de participación se define por su objeto.

Partiendo de este punto y siendo la participación en la gestión el tema de esta investigación, en un intento por definirla se analizará primero su objeto.

\subsubsection{Objeto de la participación en la gestión}

Al precisar el concepto de participación en la gestión los autores hablan de injerencia de los trabajadores en la administración de la empresa ${ }^{3}$, en la toma de decisiones ${ }^{4}$, y otras similares.

Pero, en términos jurídicos ¿qué significa esto?

En opinión de Bernardoni y Zuleta ${ }^{5}$ esta injerencia del trabajador en la administración o en la toma de decisiones en el plano jurídico implica "...que el objeto de la participación es el poder de dirección del empleador".

1 Cfr. O. Ermida, Derecho Colectivo del Trabajo: materiales de enseñanza, Lima, PUCP, 1988, p.66; T. Obregón, "La Constitución de 1993 y los trabajadores en la empresa", Asesoría Laboral, enero de 1994, p. 23; J.J. Martínez, "Círculos de Calidad ¿Participación de los trabajadores en la empresa? A propósito de los comités de Producción y Productividad", Themis, $N^{\circ} 34$ noviembre de 1996, p. 125.

2 Cfr., Oscar Ermida, Op. cit., p. 66.

3 Cfr., E. Morgado. "Participación de los trabajadores en la empresa", Análisis Laboral, marzo de 1995, p. 13.

4 Cfr., T. Obregón, Op. cit., p. 23.

5 M. Bernardoni de Govea y C. Zuleta de Merchan, Análisis sobre la cogestión y otras formas de participación, Universidad de Zulia, Maracaibo, 1985, p. 14. 
Este poder de dirección nace de la celebración de un contrato de trabajo

Por la celebración de un contrato de trabajo las partes intervinientes (trabajador y empleador) asumen obligaciones y derechos. El trabajador está obligado a prestar sus servicios al empleador, por los cuales tiene derecho a ser remunerado. El empleador, a su vez, adquiere para sí los frutos del esfuerzo del trabajador y por ello debe pagarle.

Sin embargo, el empleador no sólo debe remunerar el trabajo sino que para conseguir la utilidad que persigue el contrato, es necesario que lo dirija dando órdenes sobre el modo, lugar y tiempo en que debe realizarse. En opinión de Alonso Olea " "...tiene derecho al trabajo en sí mismo en cuanto encaminado a la obtención de los resultados queridos".

Es a este derecho, nacido de la voluntad contractual que la doctrina le denomina poder de dirección o ius variandi.

$Y$ es sobre el ejercicio de este derecho que actúa la acción participativa del trabajador.

En este sentido, la participación del trabajador en la gestión de la empresa implica compartir el poder de dirección, antes exclusivo del empleador.

\subsubsection{Sujeto de la participación en la gestión}

En cuanto al sujeto titular del derecho de participación en la gestión, el que comparte el poder de dirección del empleador, es el colectivo de los trabajadores ${ }^{7}$.

Esta es la idea que subyace en la elaboración de los instrumentos de participación ${ }^{8}$. Por ello se crean entes colectivos que representen a los trabajadores, porque éstos no tienen atribuido el poder de gestión de manera individual sino grupal.

Según lo expresa claramente Bernardoni y Zuleta " “...el sujeto titular del derecho de participación (...) es el colectivo de los trabajadores".

6 M. Alonso, Introducción al Derecho del Trabajo, 3era. Edición, Ed. Revista de Derecho Privado, Madrid, 1980 , p. 216.

7 Cfr. J.J. Martínez, Op. cit., p. 129.

8 Se tratará este tema con más detalle en el punto 1.5 de este capítulo. Baste por ahora decir que todos los instrumentos a través de los que se viabiliza la participación en la empresa implican la elección de representantes.

9 Bernardoni y Zuleta, Op. cit., p. 15. 
Concebir la participación de manera individual, no parece viable.

$\mathrm{Al}$ ser trabajador individual el sujeto titular del derecho de participación, la subordinación al empleador se pierde por completo. Cada trabajador tendría atribuida la facultad de por lo menos cuestionar las decisiones del empleador, en lo referente a la ejecución de su labor en particular.

Al ser el colectivo de trabajadores el titular del derecho de participación en la gestión, la subordinación no desaparece pues solo se está reconociendo la facultad de cuestionar las decisiones del empleador relativas a lo que se podría llamar "...las condiciones generales de trabajo", aquellas que por el grupo de trabajadores comparten. El empleador aún podrá tomar unilateralmente las decisiones que le parezca, en cuanto a la prestación del servicio de cada trabajador en particular.

\subsubsection{Derecho de participar en la gestión}

La facultad de participación del colectivo de los trabajadores es calificada de manera unánime por la doctrina como un derecho del trabajador ${ }^{10}$.

A nivel constitucional, en Latinoamérica es reconocido como tal en las constituciones de Brasil y Nicaragua ${ }^{11}$. Igualmente, en Europa, en Francia, Italia y Portugal.

A nivel legislativo, Alemania, Francia, Bélgica, Luxemburgo y Portugal, establecen que la participación en la gestión es un derecho ${ }^{12}$.

La doctrina peruana no indaga sobre el fundamento del derecho de participación. Es éste un tema que al parecer suscita poco interés en los autores, o por lo menos sobre el que hay poco interés en pronunciarse. Todos parten del hecho que está reconocido como derecho por el ordenamiento nacional y extranjero, luego se enfrascan en discusiones doctrinales sobre su correcta regulación legislativa y constitucional. Parecen aceptar como fundamento su positivación.

10 Cfr. T. Obregón, Op. cit., p. 23; J.J. Martínez, Op. cit., p. 125; T. Sala y I. Albiol, Derecho Sindical, 4ta. Edición, Ed. Tirant to Blach, Valencia, 1996, p. 186.

11 Cfr. R. Marcenaro, "El Trabajo en la nueva Constitución", en AA.VV., Serie Lecturas sobre temas Constitucionales. $N^{\circ} 10$, 1era. Edición, Lima, Ed. Comisión Andina de Juristas, 1994, p. 199.

12 Cfr. T. Sala y I. Albiol, Op. cit., p. 184. 
Este derecho, como todo derecho, puede tener como fuente la ley o el acuerdo de las partes. Asimismo, puede ejercerse en distintos grados y sobre distintas materias según lo determinen las partes o la ley. Todas estas cuestiones serán materia de los siguientes puntos.

\subsection{Fuentes de la participación en la gestión}

En doctrina la denominación de las fuentes de la participación varían. Algunos las denominan fuentes autónomas y heterónomas ${ }^{13}$, otros hablan de fuentes legales y convencionales ${ }^{14}$, pero el criterio para diferenciarlas es el mismo para todos, las fuentes se distinguen según sean impuestas o voluntarias.

Así, a grandes rasgos, un sistema de participación puede tener como origen una norma estatal o una norma o acto voluntario.

La norma legal como la denomina Ermida Uriarte ${ }^{15}$ “...la legislación en sentido amplio", pueden ser la constitución, la ley y el reglamento. Al respecto no hay mayor contradicción entre los autores, salvo la denominación de la norma, lo que depende de cada ordenamiento jurídico en particular.

Sin embargo, si hay una crítica muy difundida entre los autores ${ }^{16}$ a este tipo de fuente. $Y$ es que atendiendo a su carácter general y según lo demuestra la experiencia, la ley o el reglamento pueden no contemplar situaciones especiales que tornen inapropiadas o insuficientes los mecanismos de participación que se establecen.

En cuanto a las normas voluntarias hay discusión. Sólo debe considerar al convenio colectivo, o también al mero acuerdo entre las partes o contrato? La divergencia se origina de la consideración de que el sujeto titular de la participación puede ser el trabajador individualmente considerado. Como ya se ha comentado, en el punto 1.3 de este capítulo, no parece que el sujeto del derecho lo puede ejercer individualmente, por lo que -en estricto- la participación como derecho no tendría por fuente un contrato. En este caso parece que se tratase más

13 Cfr. Ibid., p. 183.

14 Cfr. O. Ermida, Op. cit., p. 59.

15 Cfr. Ibidem.

16 Cfr. E. Morgado, Op. cit., p. 16; y O. Ermida, Op. cit.., p. 69. 
de una delegación del patrón de algunas funciones a su subalterno, necesarias para el desempeño de su labor, caso típico del personal de dirección (decisión sobre fijar horarios de su área, por ejemplo). Pero en todo caso este tipo de contratos, permite siempre una fiscalización del patrón, quién siempre podrá modificar la orden dada por el subalterno ${ }^{17}$.

Esta dicotomía en la clasificación de las fuentes es asumida en derecho comparado. De esta manera existen países en el mundo que tienen normas legales como fuente de su sistema de participación (Alemania, Francia, Bélgica, Holanda, Luxemburgo o Portugal) ${ }^{18}$ y otros cuyas fuentes son voluntarias (por convenios colectivos nacionales: Dinamarca; por convenios colectivos sectoriales o de empresa: Irlanda o Gran Bretaña ${ }^{19}$.

\subsection{Grados o intensidad de participación en la gestión}

El derecho de participar en la gestión puede ejercerse en distintos grados, con distinta intensidad, según convengan las partes o lo establezca la ley ${ }^{20}$.

En la doctrina se reconocen varios y distintos niveles de participación que van desde el derecho a ser informados de la marcha de la empresa hasta el ejercicio pleno de la dirección de la empresa por el personal $^{21}$.

Analizaremos cada uno de ellos clasificándolos en tres grandes grupos: participación bajo la forma de cooperación o colaboración, cogestión y autogestión ${ }^{22}$.

\subsubsection{La colaboración o cooperación}

Bajo esta denominación se agrupan todas aquellas formas de participación en la cuales la intervención del personal. Sea activa o pasiva, pre-

17 Mayor explicación del tema se encuentra en el punto 1.3 de este capítulo.

18 Cfr. T. Sala y Y. Albiol, Op. cit., p. 184.

19 Cfr. Idem, p. 184.

20 Siendo ambas fuente de derecho.

21 Cfr. Manuel García Fernández, La participación del trabajador en la gestión de la empresa, Ed. Prensa Española, Magisterio Español y Editora nacional, Madrid, 1976, p. 33.

22 Cfr. Manuel García Fernández, Op. cit., pp. 57-95. 
via o posterior a la decisión del empleador no llega a ser vinculante para éste ${ }^{23}$. Dentro de este grupo se encuentran:

a) El derecho a ser informados antes de que el empleador tome una decisión: derecho de información ${ }^{24}$

b) El derecho a ser consultados de forma previa antes de que una decisión sea tomada, aunque la opinión de los trabajadores no obligue a la administración: derecho de consulta ${ }^{25} \mathrm{y}$,

c) El derecho a controlar de manera permanente la marcha general de la empresa, emitiendo críticas que deben ser escuchadas por el empleador: derecho de control ${ }^{26}$.

Considera Obregón Sevillano en una posición peculiar que éstas no son verdaderas formas de participación en la gestión ${ }^{27}$ “...porque la gestión comprende todo un proceso global que comprende el conjunto de decisiones (órdenes, sugerencias, evaluaciones, etc.) que necesita una empresa para desarrollar sus objetivos".

Contrariamente afirma García Fernández ${ }^{28}$ que “...un buen sistema de gestión participativa descansa, fundamentalmente, en la creación de un buen sistema de información (...) Junto a la creación de unos buenos canales de información se estructuran una serie de labores de asesoramiento y consulta. El resultado de todo ello es que el proceso de elaboración de una decisión es, en mayor medida, colectivo, aún cuando su adopción sea unipersonal.

23 Cfr. Oscar Ermida Uriarte, Op. cit., p. 70, Manuel García Fernández, Idem, pp. 5773.

24 Ejemplo en el Derecho Español: la competencia del comité de empresa señalada por la R.D. Leg. 1/1995, de 24 de marzo en su Art. $647^{\circ}$.- "Ser informado de todas las sanciones impuestas por falta muy graves".

25 Ejemplo en el Derecho Español: la competencia del comité de empresa señalada por la R.D. Leg 1/1995, de 24 de marzo en su Art. $644^{\circ}$ a).- "Emitir informe, con carácter previo a la ejecución por parte del empresario de las decisiones adopradas por éste sobre las siguientes cuestiones: a) Reestructuraciones de planilla y ceses totales o parciales, definitivos o temporales de aquella".

26 En Derecho Español la competencia del comité de empresa citada en la R.D. Leg. 1/ 1995, de 24 marzo en su Art. $649^{\circ}$ b).- "Ejercer una labor:

b) De vigilancia y control de las condiciones de seguridad e higiene en el desarrollo del trabajo en la empresa, con las particularidades previstas en el artículo 19 de esta Ley".

27 T. Obregón, Op. cit., p. 24.

28 Cfr. Ibid., pp. 29-30. 
Al comentar el punto de vista de García Fernández es obligado notar que el autor se refiere a la eficacia de la participación del trabajador en la empresa. Si bien en términos de eficacia puede ser que el nivel de la información sea esencial para que el sistema participativo funcione, de lo que se trata es de determinar si ese nivel comporta o no una injerencia en el poder de dirección del empleador. Vale decir, si en términos jurídicos estamos hablando de participación en la gestión.

Desde que, como lo reconoce el propio García Fernández al decir que la decisión es tomada de manera unilateral por el empleador, nos encontramos con un solo agente decisor no parece acertado decir que exista una participación en la gestión. Sin embargo, es obligado anotar que, la doctrina mayoritaria sigue considerando al nivel de la información y la consulta como una forma de ejercer el derecho de participación en la gestión ${ }^{29}$. Ello obedece a que el trabajador en estos casos participa cuando su crítica o comentario es sometido a consideración.

\subsubsection{Cogestión}

La cogestión es definida por los autores como la participación que permite que los trabajadores intervengan efectivamente en la gestión o dirección de la empresa.

Según lo explica Ermida Uriarte "implica que las decisiones no pueden ser adoptadas sin que los trabajadores hayan tomado parte en el proceso de adopción de la decisión".

Pero no supone un poder de gestión absoluto ${ }^{31}$ pues si bien es indispensable que el personal participe en el proceso de toma de la decisión, no lo es que la cuota de poder que detenta en ese proceso sea igual a la que detenta el empleador. Por eso la cogestión puede ser paritaria o minoritaria ${ }^{32}$.

Algunos autores hablan de participación mayoritaria, pero ella se asimila en sus efectos prácticos a la autogestión por lo que no se ha considerado como un tipo de cogestión. Por medio de la cogestión

29 Cfr. O. Ermida, Op. cit., p. 70; T. Obregón, Op. cit., p. 24.

30 O. Ermida, Op. cit., p. 70.

31 Como se verá más adelante, en el punto 3.3 de este capítulo, esto implicaría una participación autogestionaria.

32 Cfr. T. Obregón, Op. cit., p. 24. 
mayoritaria no se pueden tomar decisiones contrarias a la opinión de los trabajadores, por lo que en la práctica el poder de dirección es exclusivo de éstos. Es minoritaria cuando los trabajadores están en minoría ante el empleador por lo cual la decisión puede ser adoptada con su participación pero eventualmente contra su opinión. Es paritaria cuando el peso de la opinión de una y otra parte es el mismo, con lo cual ninguna decisión puede ser adoptada sin el acuerdo entre las partes.

\subsubsection{Autogestión}

En este caso es el personal el que de forma exclusiva y excluyente, dirige la empresa.

El colectivo de los trabajadores ejerce el poder de dirección de manera exclusiva.

En opinión de García Fernández ${ }^{33}$, constituye el más avanzado de los medios de participación del trabajador. Mientras que Ermida Uriarte $^{34}$ cuestiona la validez de la calificación de la autogestión, como forma de participación en la gestión. Argumenta que es discutible que en este caso se pueda hablar propiamente de participación desde que en la autogestión se desplaza a una de las partes, la que es íntegramente sustituida por la otra y no parece posible participar sino entre dos.

En efecto, al definir el objeto del derecho de participación ${ }^{35}$ quedo claro que la participación en la gestión importaba compartir ese poder de dirección antes exclusivo del empleador.

Se hizo referencia a la palabra compartir porque de asumir por completo los trabajadores el poder de dirección se desnaturalizaría el contrato de trabajo, ya no estaríamos ante una relación de tipo laboral (entre trabajadores y empleados) pues cualquier nivel de subordinación por parte del trabajador se pierde, perdiéndose así la característica fundamental del contrato de trabajo ${ }^{36}$.

33 Cfr. M. García, $O p$. cit., p. 85.

34 Cfr. O. Ermida, Op. cit., pp. 70-71.

35 En el punto 1.2 de este capítulo.

36 Como contraparte al poder de dirección del empleador. 


\subsection{Materias de participación en la gestión}

El objeto de la participación en la gestión es el poder de dirección del empresario, el cual puede estar referido a cualquiera de los cuatros sectores, en que suele clasificarse la actividad empresarial ${ }^{37}$ :

El sector económico o financiero (previsiones y programas de producción e inversión, reparto de beneficios, reservas, etc.); sector técnico, referido a las condiciones técnicas de producción o distribución de bienes o servicios; sector profesional, referido a las condiciones de empleo del personal (ingresos, traslados, jornada, disciplina, despidos); sector social, referido a las denominadas obras o servicios sociales (comedores, escuelas, fundaciones, mejoras de seguridad social, etc.)

Sin embargo, reconoce la doctrina que en líneas generales existe, en el derecho comparado, una tendencia a instaurar formas participativas alrededor de los sectores profesional y social, siendo menor la tendencia en los demás sectores ${ }^{38}$. Considera la doctrina que la tendencia es menor en estos sectores porque "...tales temas son considerados como el núcleo tradicional de las prerrogativas de la empresa". Al igual que es menor la intensidad con que en los sectores económico y técnico se permite la participación.

\subsection{Instrumentos de participación en la gestión}

Se considera que existen dos modelos participativos, uno denominado orgánico o institucional y otro denominado inorgánico o conflictivo. La diferencia estriba en la forma de constitución de ambos, la naturaleza de su función, y los medios que tienen para alcanzar sus objeti$\operatorname{vos}^{39}$.

El primero es el constituido por órganos ajenos a la estructura sindical, cuyos miembros son elegidos por todos los trabajadores de la empresa. El segundo es el constituido por órganos sindicales, elegidos por los afiliados al sindicato.

La participación conflictiva nace como la primigenia forma de representación de los trabajadores, ante la necesidad de la reivindicación

37 Cfr. T. Sala y Y. Albiol, Op. cit., p. 183.

38 Cfr. E: Morgado, Op. cit., p. 16.

39 Cfr. E. Ermida, Op. cit., p. 71; Sala, T. Y Albiol, I., Op. cit., p. 183. 
de sus derechos mínimos. El sindicato se muestra como una manera de contratar las condiciones de trabajo en una posición de igualdad, al menos teórica, entre trabajadores y empresario. Es un nivel primigenio de gestión en el sentido de que no permite usar al empleador su poder de dirección de forma abusiva.

La participación institucional nace como una forma alternativa de representación a la sindical. Por ser posterior históricamente, no reducirá su función a un plano reivindicativo sino que regulará junto con el empleador las relaciones de trabajo, en cuestiones no siempre referidas a mínimos laborales. Así, por ejemplo, en la República Federal Alemana el consejo de empresa debía aprobar los cuestionarios relativos al personal, es decir los principios de evaluación ${ }^{40}$. Ello implica una regulación en positivo, algo más que una regulación de mínimos laborales.

En razón a su función, los medios que utiliza para alcanzar sus objetivos son también distintos. En la participación conflictiva la falta de acuerdo en un proceso negociador, que no es otra cosa que un proceso de toma de decisiones, va acompañado normalmente de la huelga; mientras que la falta de acuerdo en un mecanismo de participación institucional (de consulta o codecisión), y concluye normalmente en un arbitraje. En las empresas de la RFA con más de cinco trabajadores estables se le denominaba el órgano de conciliación ${ }^{41}$.

Parece válido afirmar que ésta última comporta un nivel más perfecto de gestión en el sentido de que comparte el poder de dirección del empresario, no simplemente lo limita en el ejercicio abusivo del mismo.

Hasta aquí se entiende bien que la participación en la gestión puede revestir estas dos formas. En adelante centraremos nuestro estudio tan solo en forma institucional por ser el tema de nuestra investigación.

40 Cfr., Con lo dispuesto en los Arr. 1 y 94 de la Ley de 15 de enero de 1972 sobre Organización de las empresas, trad. Cast. Instituto de Estudios Económicos. La participación de los trabajadores en la empresa, Madrid, Ed. Instituto de Estudios Económicos, 1970, pp. 69 y 88 .

41 Cfr., lo dispuesto en el Art. $76^{\circ}$ de la Ley del 15 de enero de 1972 sobre Organización de la empresas, trad. Cast. Instituto de Estudios Económicos, Op. cit. p.84 


\subsubsection{Participación institucional en la gestión}

En este punto nos remitimos a lo expuesto en el punto 1.5 agregando que ésta puede ser interna o externa, y ésta última, a su vez, unipersonal o colegiada ${ }^{42}$.

\subsubsection{Participación institucional interna}

La participación institucional interna consiste en la integración de representantes laborales en los órganos directivos de la empresa. No hay un órgano participativo propiamente dicho, sino que la participación se hace en los órganos de dirección propios de las diversas formas jurídicas que adoptan las empresas (sociedad anónima, sociedad de responsabilidad limitada, etc. $)^{43}$. La integración de los trabajadores en los órganos de dirección es generalmente minoritaria ${ }^{44}$, pero se registran casos de composición paritaria, como en la industria minera y siderúrgica $^{45}$ y en todas las empresas de más de 2000 trabajadores de la RFA ${ }^{46}$.

Esta fue la forma adoptada en el Perú, por el antiguo régimen ${ }^{47}$.

\subsubsection{Participación institucional externa}

La participación institucional externa es la forma más típica de participación orgánica ${ }^{48}$.

Consiste en la creación de órganos diferentes a los órganos directivos de la empresa. Son calificados como "órganos participativos por excelencia", no en el sentido que sean mejores que la participación

42 Cfr. O. Ermida, Op. cit., p. 72; Manuel García Fernández, Op. cit., pp. 57-70.

43 Cfr., O. Ermida, Op. cit., p. 74

44 Cfr., O. Ermida, Op. cit., p. 71

45 Cfr., Con lo dispuesto en los Arts. $1.1^{\circ}, 4.1^{\circ}$ y $13.1^{\circ}$ de la Ley de 21 de mayo 1951 , sobre Cogestión de los trabajadores en los Consejos de Vigilancia y Directorios de las empresas de minería, carbón y empresas productoras de hierro y acero, trd. Cast. Institutos Económicos, Op. cit., p. 105 y 107.

46 Cfr., Con lo dispuesto en los Arts. 1,7. y 33 de la Ley de 4 de mayo, sobre Cogestión de los trabajadores, trd. Cast. Institutos Económicos, Op. cit., pp. 125-127 y 133.

47 En el régimen anterior al Dec. Leg. 677 (02-10-91), regido por los decretos leyes $21798,22329,22333$ y 19020 que establecían representantes de los trabajadores en los órganos directivos.

48 Cfr. M. García, Op. cit., p. 74. 
interna, sino en el sentido de que su función exclusiva o primordial es la participación.

Estos pueden clasificarse en unipersonales o colegiados.

El órgano unipersonal es un delegado de personal o delegado de empresa, fórmula que generalmente se reserva para las empresas cuyo número de trabajadores es inferior a una determinada cifra, sobrepasada la cual se impone el órgano colegiado ${ }^{49}$. No obstante, puede darse que en las empresas con personal superior al tope en cuestión, coexisten el órgano colegiado principal con delegados del personal que se le atribuyen cometidos específicos adicionales. Este era el caso de los delegados de personal y adolescentes en las empresas de la RFA ${ }^{50}$.

El órgano colegiado puede tener distintas denominaciones según los distintos sistemas nacionales (en Francia y España se les llama comités de empresa; en Italia, comisiones internas; en Holanda y en la RFA se les denomina consejos de empresa) ${ }^{51}$.

En opinión de García Fernández ${ }^{52}$ “...pueden ser unitarios o mixtos, en el sentido de ser compuestos exclusivamente por trabajadores o compuestos por representantes de los trabajadores y de los empleadores (en número equivalente o dispar)".

La designación de los delegados del consejo de empresa puede ser hecho directamente por el personal (reunido en asamblea o por sufragio directo), por el sindicato o en forma mixta (por ejemplo por el personal uno y otro por el sindicato, o todos los delegados por el personal pero sobre listas propuestas por el sindicato o designación sindical sobre nóminas propuestas por el personal) $)^{53}$.

Las atribuciones de los miembros de los consejos de empresa dependen, en rigor, del grado de participación que le ha otorgado la norma legal o convencional al órgano en cuestión.

49 Cfr., O. Ermida, Op. cit., p. 72.

50 Cfr., Arts. $32^{\circ}$ y $60^{\circ}$ de la Ley del 15 de enero de 1972, trad. cast., Instituto de Estudios Económicos, Op. cit., pp. 75 y 80.

51 Cfr., Ibid., pp. 9,27,43,69 y 137.

52 M. García, Op. cit., pp. 59-60.

53 Cfr., O. Ermida, Op. cit., p. 72. 


\section{Panorama jurídico peruano}

Como se planteara en un principio se hace necesario para el análisis del sistema jurídico peruano en materia de derecho de gestión, el conocimiento del tratamiento del tema en el derecho comparado, y por la doctrina autorizada. Con estos datos, esbozados en el capítulo antecedente, se pasará a identificar las características del planteamiento peruano en este tema.

\subsection{Planteamiento constitucional}

A nivel constitucional nuestro ordenamiento contempla el tema de la participación de los trabajadores en su Art. $29^{\circ}$, que dice a la letra:

"El Estado reconoce el derecho de los trabajadores a participar en las utilidades de la empresa y promueve otras formas de participación" $" 4$

Como se comprueba de su lectura, el texto constitucional no hace referencia al derecho de gestión, al menos no textualmente, como si se hizo en la Constitución de $1979^{55}$. Tampoco se precisa qué formas de participación son las que el Estado tiene obligación de promover.

En relación con esto último opina Marcenaro Frers ${ }^{56}$ que "...el constituyente asume una actitud moderada al no obligar a las empresas a otorgar participación en la gestión y propiedad." ${ }^{7}$, infiere el autor, como lo hace la mayoría de la doctrina consultada ${ }^{58}$, que esta frase alude al derecho de participación en la gestión y propiedad del trabajador, interpretación que, en opinión de Enrique Bernales, no es la única. El citado autor opina que si bien "... el artículo permite otras

54 Artículo 29 de la Constitución de 1993.

55 Art. 56" "El Estado reconoce el derecho de los trabajadores a participar en la gestión y utilidad de la empresa, de acuerdo con la modalidad de ésta. La participación de los trabajadores se extiende a la propiedad de las empresas cuya naturaleza jurídica no lo impide".

56 Presidente de la Comisión de Trabajo y Seguridad del CCD, encargada de la modificación de la Constitución de 1979 en la parte percinente.

57 R. Marcenaro, Op. cit., p. 198.

58 Cfr., T. Obregón, Op. cit., p. 25; E. Bernales, Op. cit., p. 230; C. Blancas, Op. cit., p. 108 . 
formas de participación del trabajador en la empresa, probablemente en la gestión y tal vez en la propiedad... no es específico en la materia y por tanto queda como una posibilidad sujeta a varias interpretaciones y aplicación".

Tal parece ser que en la fuerza argumental de la posición que ve el reconocimiento del derecho de gestión en este artículo, estaría en una interpretación extensiva del mismo, que considera su antecedente constitucional. Sin embargo, coincidimos con Enrique Bernales y consideramos que tal no ha sido el espíritu de la ley. Que si bien el constituyente no niega el derecho de gestión al trabajador, tampoco se lo ha querido reconocer expresamente, como si se ha hecho en materia de participación en utilidades. De lo contrario, no se entiende la modificación constitucional.

Sin embargo, aún poniéndonos en el supuesto que el legislador con esta frase haya querido referirse a la participación en la gestión y la propiedad ¿qué significa que el Estado promueva la participación en la gestión?, ¡cuáles serían los efectos jurídicos de tal disposición constitucional?

En este punto sorprende la claridad de Obregón Sevillano ${ }^{59}$ al decir que no significa que se niegue el derecho a participar en la gestión, sino que no se obliga al legislador a establecerlo vía infraconstitucional "...es decir, si por legislación posterior se establece el derecho de los trabajadores a participar en la gestión ello cabría al amparo de la Constitución. Pero, asimismo, si no se llegara a establecer, ello no sería inconstitucional".

Sobre el particular y tal vez por aquella "animadversión" del sistema sobre la que advirtiéramos al inicio, no se han vertido mayores comentarios. Es así que, en nuestra opinión, los efectos jurídicos de esta lectura constitucional no serían otros que la desaparición, o por lo menos la restricción de la posibilidad que el derecho de gestión se vea protegido vía acciones de garantía. Un ejemplo hipotético puede ilustrar nuestro punto de vista. ¿Ante la dación de una ley que derogue el derecho de participación, actualmente reconocido por el Dec. Leg. No 677 , se podría hablar de inconstitucionalidad de la misma? Probablemente en la parte tocante al derecho de participación en las utilidades

59 Cfr., Ibid. p. 26. 
el tema merecería una rotunda afirmación, pero en cuanto al derecho de gestión, la respuesta no es tan clara. La constitución señala que el Estado está obligado a promover otras formas de participación, ¿̇debe hacerlo vía legislativa, o se trata de decisiones políticas a nivel ejecutivo que fomenten la participación? Ante esto parece acertado decir que, en principio, no se podría afirmar la inconstitucionalidad de esa ley, desde que no hay expresa contradicción con lo dispuesto por la Constitución. Creemos que el mismo razonamiento puede aplicarse en la contestación al ejercicio de otras acciones de garantía, en refuerzo de nuestra posición.

Avanzando con nuestra investigación se comprueba que, el texto constitucional no se pronuncia sobre la fuente de la que emana la participación en la gestión. Al respecto Enrique Bernales apunta que si bien no hay obligación de legislar al respecto, nada en el texto constitucional impide el establecimiento, vía convenios colectivos, de este derecho. Y, coincidiendo con él, añade Marcenaro Frers ${ }^{60}$ que esta es la manera más adecuada de regular el tema de la participación. El Estado no debe imponerla sino propiciar que sea producto de la voluntad de las partes.

Tampoco se desarrolla el grado o intensidad con que ésta se ejercerá, ni sobre las materias en que incidirá la misma. No se hace mención al instrumento a través del cuál la participación será viable. Y si bien, en este último caso la legislación infraconstitucional ha escogido el sistema institucional, nada en la legislación constitucional impide a las partes optar dentro de él por cualesquiera de sus variantes ${ }^{(1)}$.

En este orden de ideas, es interesante anotar, que si bien el desarrollo legislativo del Art. $29^{\circ}$ de la Constitución, apuesta por una opción institucionalizada del ejercicio del derecho de gestión, el Art. $28^{\circ}$ de la misma $^{62}$ reconoce los derechos de sindicalización, negociación colecti-

60 Cfr. R. Marcenaro, Op. cit., p. 199.

61 Según quedo explicado en el punto 3 del capírulo 2.

62 Artículo $28^{\circ}$.- "El Estado reconoce los derechos de sindicación, negociación colectiva y huelga. Cautela su ejercicio democrático:

1. Garantiza la libertad sindical.

2. Fomenta la negociación colectiva y promueve formas de solución pacífica de los conflictos laborales. La convención colectiva tiene fuerza vinculante en el ámbito de lo concertado.

3. Regula el derecho de huelga para que se ejerza en armonía con el interés social. Señala sus excepciones y limitaciones." 
va y huelga. Es decir la participación inorgánica o conflictiva del trabajador es un derecho de rango constitucional y goza de toda la protección que ello implica y que hemos ya comentado, por lo que será siempre un sistema obligatorio a instaurar en una relación laboral que se ajuste a derecho.

\subsection{Planteamiento legislativo}

Al nivel legislativo es el Decreto Legislativo $677^{63}$ el que regula el derecho de participación en el derecho peruano, como lo explican sus consideraciones previas ${ }^{64}$, sus disposiciones configuran el sistema jurídico peruano en materia de participación en la gestión. Sin embargo, creemos que no es la única norma a consultar sobre el tema. El Decreto Legislativo $892^{65}$ que modifica la participación en las utilidades, es relevante, puesto que incide en el tratamiento legal del tema, la misma que hasta hoy no ha sido estudiada por la doctrina especializada.

De esta manera, el Dec. Leg. No 677 norma el derecho de participar en la gestión del trabajador, en la siguiente forma.

Según su Art. primero ${ }^{66}$ (67) gozan del derecho a participar en la gestión todos los trabajadores de empresas sujetas al régimen laboral de la actividad privada cuyas actividades resultaran generadoras de renta de tercera categoría ${ }^{67}$. Sin embargo, se excluyen de este grupo a las empresas autogestionarias, cooperativas y comunales, las individuales, las sociedades civiles y en general todas aquellas que no exceden de veinte trabajadores, según lo disponía su artículo décimo (68). Igual-

63 Decreto Legislativo 677 promulgado el 07 de octubre de 1991. En adelante Dec. Leg. 677.

64 "Que a fin de promover la inversión en todos los sectores de la actividad económica y al mismo riempo integrar a los trabajadores en un proceso de participación que aumente el empleo y le permita invertir en forma libre en las empresas a que pertenecen, es necesario sustituir los diversos regímenes de participación laboral existentes por un régimen común cuya aplicación se extienda a todas las empresas generadoras de renta de tercera categoría".

65 Decreto Legislativo 892 promulgado el 11 de noviembre de 1996. En adelante Dec. Leg. 892.

66 Art. 1 "El presente Decreto Legislativo, regula la participación en la utilidad, gestión y propiedad de los trabajadores de las empresas que desarrollen actividades generadoras de Renta de Tercera Categoría y que están sujetos al régimen de la actividad privada".

67 Cfr. Art. $28^{\circ}$ de Dec. Leg. 774 (31/12/93). 
mente, se encuentran fuera de su ámbito de aplicación las empresas establecidas en las zonas francas industriales o turísticas, en virtud de lo dispuesto por el artículo 16 del Decreto Legislativo $704^{68}$.

El derecho de participación en la gestión era definido en su Art. $6^{\circ}$. Se establece que los trabajadores participan de la gestión a través de comités destinados a mejorar la producción y productividad de la empresa. Estos serán integrados por no menos de dos representantes de la empresa y por un representante de los trabajadores.

En torno a esta disposición surge la discusión sobre la naturaleza de estos comités, siendo principalmente dos las opiniones vertidas. Unos opinan que se trata de un intento por introducir a nuestra legislación los conocidos círculos de control de calidad japoneses ${ }^{69}$, ahora también adoptados por los Estados Unidos (como es el caso de la General Motors), y otros opinan que se trata más bien de copiar los comités o consejos de empresa existentes en Europa ${ }^{70}$.

Analicemos estas dos posibilidades.

La primera, afirma que estos comités de producción y competitividad serían los denominados círculos de calidad. Estos son mecanismos a través de los cuáles se hace efectiva la calidad total en la empresa. Se trata de pequeños grupos de trabajadores pertenecientes a una misma sección, que voluntariamente se reúnen periódicamente y en el centro de trabajo, para estudiar problemas concretos (uso de herramientas, agilización de la producción, etc.) que se presentan en la labor diaria. En esas reuniones se determinan las causas de dichos problemas, se proponen soluciones, se toman acuerdo por consenso y se ejecutan. Los trabajadores participan en la adopción de decisiones, aunque dentro de una esfera limitada ${ }^{71}$.

Esta posición basa su afirmación en que se trata de varios comités, por lo que se supone pueden estar conformados por uno o más miembros de los estamentos que conforman la organización empresarial y

68 Dec. Leg. 704, Artículo 16\%.- "Las empresas establecidas en las zonas francas industriales o turísticas, en razón de su especial naturaleza, quedan exceptuadas de aplicar los regimenes de participación a que se refiere el Decreto Legislativo $N^{\circ} 677^{\prime \prime}$.

69 AA.VV., "Participación en las Utilidades Gestión y Propiedad de las empresas: Dec. Leg. $N^{\circ}$ 677", Análisis Laboral, Octubre de 1991, p. 18.

70 Cfr. J.J. Martínez, Op. cit., p. 130.

71 Cfr., E. Ogliastri, Gerencia Japonesa y Círculos de participación, Experiencias en América Latina, Ed. Norma, Bogotá, 1988, pp. 27-28. 
que sean compatibles con el asunto a tratar ${ }^{72}$ (por ejemplo los del área de mantenimiento de los motores en una fábrica).

La segunda opinión surge de la similitud de los nombres que las mismas formas de participación, de tipo institucional externo, han recibido en Europa ${ }^{73}$ y del hecho de ser formas jurídicas de implementación del derecho de gestión.

Los círculos de calidad son fórmulas organizacionales, de muy buen resultado en Europa y Norteamérica, pero que no están consagrados en la legislación de esos países.

Aunque parece más sólida la primera posición, es interesante anotar la opinión de Martínez Ortiz ${ }^{74}$ cuando hace un análisis del proceso de adopción de las decisiones en los círculos de calidad: "Si bien en un sentido lato (no técnico) puede decirse que el trabajador "participa" o "interviene" en las decisiones de la empresa, debe tenerse presente que tal acción no tiene un contenido jurídico sino funcional y consiste en la delegación (...) de funciones realizada por el titular de la empresa". Para Martínez el empresario, forzado por los cambios que se están produciendo, opta por ejercer su poder de dirección de cierto modo, respecto de su personal subordinado. No existe un cuestionamiento al poder empresarial, ni la atribución de un derecho al colectivo laboral, solamente existe una descentralización de funciones que se hace efectiva de manera individual y eventualmente grupal. En los círculos de calidad no se cuestiona el poder de dirección del empresario, quien siempre puede modificar unilateralmente el acuerdo tomado por los trabajadores.

Por nuestra parte, anotaremos que el Dec. Leg. en cuestión no hace referencia a la intensidad de la participación del trabajador, si ésta es de tipo cogestionaria o a nivel de colaboración o cooperación. Establece si el instrumento a utilizar para participar: comités destinados a mejorar la producción y productividad, es decir un órgano diferente a los de la estructura jurídica de la empresa, y conformado por tres miembros, la participación es de tipo institucional externa colegiada. Señala además la conformación del comité, dos miembros del empleador y un repre-

72 Cfr. Alfredo Chianda Quiroz, "Participación de los trabajadores en las utilidades, patrimonio y gestión de las empresas", Análisis Laboral, junio, 1992.

73 Cfr., la doctrina citada a pie de página del punto 1.3 del primer capítulo.

74 Ibid., p. 129. 
sentantes del colectivo, es decir que este órgano colegiado es mixto en número impar, ciñéndonos a la clasificación hecha con anterioridad. No hay regulación sobre la forma de designación ni de las atribuciones de este ente, remitiéndose en este último asunto expresamente al Reglamento para su tratamiento. Se aparta el ordenamiento peruano, de la forma de participación existente hasta entonces, que era de tipo interno y unipersonal (participación de un representante de los trabajadores en el directorio) ${ }^{75}$.

En todo caso, si bien la ley señala la forma estructural de los mismos, se remite al Reglamento para que se regule su funcionamiento. El Reglamento del Decreto Legislativo No 677 sería dictado por el Ejecutivo, no determinándose un plazo máximo para ello, según su sexta disposición final y transitoria ${ }^{76}$. Esta remisión al reglamento ocasionó que desde 1992 (año desde que entra en vigencia en nuevo régimen por disposición del Art. $6^{\circ}$ ), los trabajadores no ejercieran su derecho de gestión, pues el anterior régimen de participación había quedado derogado, y el nuevo Reglamento no se ha dictado hasta la fecha.

\subsubsection{Planteamiento Legislativo después de la promulgación del Dec.} Leg. 892.

El espíritu que anima la promulgación del Dec. Leg. 892 es el de modificar el régimen de participación en las utilidades para fomentar condiciones que estimulen la creación de nuevos puestos de trabajo, incentiven inversiones y aumenten la competitividad internacional de nuestra economía. Según lo estipulan las consideraciones de la nor$\mathrm{ma}^{77}$. Con esta finalidad el Dec. Leg. 892 realiza varias reformas al

75 Cfr. Ibid., p. 130; AA.VV. "Participación en las utilidades de la empresa", Análisis Laboral, diciembre de 1996, p. 9.

76 Sexta.- "Por decretos supremos refrendados por el Ministro de Economía y Finanzas y los Ministros de los Sectores Productivos, se dictará las normas complementarias para la aplicación del presente Decreto Legislativo".

77 "Que, la participación de los trabajadores en la distribución de las utilidades tiene por objeto buscar la identificación de éstos con la empresa y por ende en el aumento de la producción y productividad de sus centros de trabajo; Que, resulta necesario modificar el sistema de participación para fomentar condiciones que estimulen la creación de nuevos puestos de trabajo, y que incentiven inversiones y aumenten la competitividad internacional de nuestra economía". 
régimen de participación en las utilidades ${ }^{78}$, reformas que no serán estudiadas por no guardar mayor interés con el tema que se investiga.

En este sentido concuerda la doctrina que el Dec. Leg. 892 solo introduce modificaciones en el ámbito de la participación en las utilidades. Los regímenes de participación en la gestión y en la propiedad no han sido alterados por él, por lo tanto rigen en estas materias lo originariamente dispuesto por el Dec. Leg. 677.

Sin embargo, según nuestra modesta opinión los cambios introducidos sí afectan a la participación en la gestión. Sustentamos nuestro punto de vista en lo dispuesto por la segunda disposición complementaria, derogatoria y final del Dec. Leg. 892.

Segunda.- "Derógase los Artículos Primero, Segundo, Tercero, Cuarto. Quinto y Primera Disposición Final y Transitoria del Decreto legislativo $\mathrm{N}^{\circ}$ 677; la Ley 11672 y sus disposiciones complementarias sobre Asignación Anual Sustitutoria de Participación de Utilidades, y la Sexta Disposición Complementaria, Transitoria, Derogatoria y Final del Texto Unico Ordenado de la Ley de fomento del Empleo".

Como se lee, esta Segunda Disposición manda se derogue el artículo primero del Dec. Leg. 677, precisamente el que delimita su ámbito de aplicación ${ }^{79}$, quedando reemplazado por el nuevo texto, que dice a la letra:

Artículo $1^{\circ}$.- "El presente Decreto Legislativo regula el derecho de los trabajadores sujetos al régimen laboral de la actividad privada, a participar en las utilidades de las empresas que desarrollan actividades generadoras de rentas de tercera categoría".

Como se puede apreciar el artículo no menciona el derecho de participación en la gestión, como sí lo hacía su antecedente. Se limita a regular el derecho de los trabajadores a participar en las utilidades.

78 Cfr. AA.VV., "Modifican régimen de participación en las utilidades", Análisis Laboral. Noviembre de 1996, p. 13.

79 Delimitado por el artículo primero del Dec. Leg. 677, que mantiene su vigencia. Su texro fue citado en el punto 2.1 de este capítulo. 
Creemos que el nuevo texto del artículo ha introducido la posibilidad de una interpretación de la ley, inexistente antes de la modificación: el que se entienda que el Dec. Leg. 677 ha reducido su ámbito de aplicación, que ahora no regula el derecho de los trabajadores a la gestión. Y puesto que ninguna otra norma de nuestro ordenamiento (Constitución, ley, o reglamento) lo regula -al menos no expresamente-, podría incluso llegarse a decir que el ordenamiento peruano no reconoce a los trabajadores el derecho a participar de la gestión.

Sin embargo, está el hecho que el artículo seis del Dec. Leg. 677 mantiene su vigencia , para poder afirmar que cuando el artículo citado hace mención a los "trabajadores de las empresas comprendidas en la presente Ley", se está refiriendo a los trabajadores de las empresas que generan rentas de tercera categoría bajo el régimen de la actividad privada, puesto que esas son las empresas mencionadas en el nuevo artículo primero, además las únicas empresas que se mencionan a lo largo del decreto vigente (es decir el nuevo texto del Dec. Leg. 677, después de las modificaciones introducidas por el Dec. Leg. 892).

Además está la consideración del artículo diez de la ley ${ }^{80}$, que excluye solo a los trabajadores de determinadas empresas, enumerándolas taxativamente. Una interpretación contraria a esta disposición establece el ámbito de aplicación del Decreto.

También está la constatación de la evidente incongruencia que se generaría al interior del Dec.Leg. 677, si por una parte se regula el ejercicio del derecho a participar de la gestión (con el artículo seis vigente) y por otra no se identifica a los sujetos capaces de ejercer tal derecho (con el artículo primero modificado). ¿Si no hay titulares del derecho de participación, quién utilizará los instrumentos de participación?

También se debe tener en cuenta el espíritu de la modificación del Dec. Leg. 677, que queda de manifiesto en sus consideraciones previas $^{81}$.

Considerar la reducción del ámbito de aplicación del Decreto, sería el equivalente a haber derogado el artículo seis, desconociendo todo

80 Art. $10^{\circ}$.- "Se encuentran excluidas de la participación en la gestión, las empresas autogestionarias, cooperativas y comunales, las individuales, las sociedades civiles y en general todas aquellas que no excedan de veinte (20) trabajadores".

81 Citadas en pie de página 77. 
derecho de participación en la gestión. Sin embargo, el legislador no ha derogado el artículo seis, éste mantiene su vigencia.

Se puede agregar, incluso, un argumento de Derecho Constitucional. Nuestra Constitución reconoce que en la relación laboral rige el principio de interpretación favorable al trabajador, en caso de duda insalvable sobre el sentido de una norma (Art. 26 Inc. 3) ${ }^{82}$, de tal manera que si un empleador, que hubiese implementado la participación, negase a sus trabajadores el ejercicio de su derecho, argumentando que el Dec. Leg. 677 ya no reconoce ese derecho, nada impide que el juez -si la discusión llegará a sede judicial- resuelva aplicando la norma constitucional citada. Dado este caso se puede argumentar que el texto del artículo sexto del Dec. Leg. 677 puede ser interpretado por lo menos en dos sentidos: uno que reconoce derechos, otro que los niega.

En este caso la duda versaría sobre el sentido de la frase "Los trabajadores de las empresas comprendidas en la presente ley" que debería ser interpretada en el sentido más favorable al trabajador, es decir en el sentido que le reconoce algún derecho, en este caso concreto, el derecho de participar en la gestión. Debe entenderse que las empresas a que hace referencia el Dec. Leg. 677 son las mismas mencionadas en el artículo primero del Dec. Leg. 892 (se entiende que la sentencia que acogiese este criterio solo tiene efecto inter partes).

Creemos que ésta es la interpretación más razonada, por lo expuesto, del sentido de la modificación introducida por el Dec. Leg. 892 y que aunque no es menos grave se trata de un error de técnica legislativa que debe superarse.

\section{Conclusiones}

Primera

La participación en la gestión es un derecho de los trabajadores que se manifiesta en el poder compartir el poder de dirección, antes exclusivo

82 Artículo $26^{\circ}$.- "En la relación laboral se respetan los siguientes principios : (...)

3. Interpretación favorable al trabajador en caso de duda insalvable sobre el sentido de una norma". 
del empleador, y así limitar el ius variandi que tiene éste sobre la prestación de la labor.

\section{Segunda}

El sujeto titular del derecho de participación en la gestión es el colectivo de los trabajadores, no el trabajador individual, desde que por definición el derecho de participación limita, más no elimina, el ius variandi del empleador. De ser el trabajador individual el sujeto titular, la subordinación al empleador desaparecerá y con ella su antecedente inmediato, el poder de dirección. Por ello, la participación en la gestión solo es posible a través de representantes del colectivo, cuya gestión versa sobre las llamadas "condiciones generales de trabajo".

\section{Tercera}

Este derecho es reconocido al colectivo de trabajadores, por el imperio de la ley o por el acuerdo de partes. En el primer caso, es la ley en sentido amplio -Constitución, ley o reglamento- la que limita el ejercicio del poder, en el segundo la convención colectiva.

\section{Cuarta}

Existen dos niveles en el ejercicio del derecho de gestión: la cogestión y la colaboración o cooperación. El nivel de la autogestión se excluye por definición, ya que sólo parece posible participar entre dos o más. La mayor intensidad participativa radica en la cogestión, desde que se exige un consenso para la adopción de las decisiones. La colaboración o cooperación es también un modo de ejercer el derecho de gestión, pero de menor intensidad dado que la crítica o sugerencia del trabajador no siempre será sometida a consideración.

\section{Quinta}

Se acepta que el derecho de gestión limita el poder de dirección en todos los sectores de la actividad empresarial, pero no en todos con la misma intensidad. En líneas generales, existe en el derecho comprado una tendencia a instaurar formas de cogestión alrededor de los sectores profesional y social: y en los sectores económico y técnico a reconocer sólo el nivel de colaboración o cooperación, en su especie de derecho de información y consulta. 
Sexta

Los instrumentos a través de los cuáles se canaliza la acción participativa del trabajador, son de dos tipos: conflictivos e institucionales. Los conflictivos son los sindicatos, los institucionales las entidades organizadas exclusivamente para tal fin, sea dentro de la estructura formal de la empresa o fuera de ella (órganos directivos o consejos de empresa). Ellos se diferencian en la modalidad de su acción participativa, los primeros participan de modo reivindicativo (buscan reivindicar los mínimos laborales), los segundos buscan regular la relación laboral más allá del respeto a unos mínimos laborales. Se singularizan por su diferente conformación y por el reconocimiento de la libertad sindical a los primeros.

\section{Séptima}

En el ordenamiento jurídico peruano, según el estado actual de la normativa constitucional, el derecho de participación en la gestión no tiene protección, es decir, no goza del amparo de las acciones de garantía. Así, ante la eventual ley que lo prohibiera o restringiera, la acción de inconstitucionalidad que pretendiera atacarla no prosperaría.

No parece sólido el argumento que en este caso proponga en contrario, que la Constitución establece la obligación del Estado de promover otras formas de participación, además de la participación en utilidades, pues el texto del Art. 29 no se sigue necesariamente que ello se refiera a la participación en la gestión.

Se tiene claro que la disposición no prohíbe el reconocimiento de tal derecho, por lo que puede establecerse vía infraconstitucional o por medio de convenios colectivos, más no por contratos individuales.

\section{Octava}

En el plano legislativo, el reconocimiento del derecho de gestión es cuestión opinable. La incongruencia legislativa, generada al interior del Dec. Leg. 677 por las modificaciones que le hiciera el Dec. Leg. 892, han abierto esta posibilidad. Es un error de técnica legislativa que ocasiona más de una interpretación válida del sentido de la norma. Nuestra posición apuesta por una interpretación sistemática de la norma 
que reconozca derechos, es decir, estamos por el reconocimiento a nivel legal del derecho de gestión en el ordenamiento peruano.

\section{Novena}

La ley reconoce el derecho de participar en la gestión a través de órganos institucionales externos, los llamados "comités de producción y productividad" cuya naturaleza jurídica parece ser la de los consejos de empresa europeos, pero bajo la adopción de la forma de los círculos de calidad japoneses. Son órganos colegiados, cuya integración es de tipo mixto e impar (un representante de los trabajadores y dos del empleador).

A pesar de que el sistema está estructurado, no ha sido puesto en funcionamiento debido a la falta del Reglamento que lo implemente.

\section{Propuesta de solución}

Se debe corregir el error de técnica legislativa, modificando el artículo primero del Dec. Leg. 892, devolviéndole de esta manera el régimen de participación de congruencia que tenía con la anterior redacción del artículo primero. La manera más idónea de hacerlo sería repitiendo el texto del derogado artículo.

Es urgente, luego de dado este primer paso, la promulgación del Reglamento del Dec. Leg. 677, que espera en el tintero hace cinco años.

Este Reglamento deberá necesariamente referirse a las siguientes materias, y en este orden de importancia:

a. Definir el grado o intensidad en que los trabajadores participarán de la marcha empresarial: serán cogestores o colaboradores, o si serán en parte uno y lo otro, como sucede en el derecho comparado.

b. Definido lo primero, se debe puntualizar en qué materias se ejercerá la cogestión, y en qué otras el derecho de ser informado o consultado previamente.

c. En base a los dos puntos anteriores, redactar las atribuciones generales de los representantes del colectivo en los comités (protección 
de fuero sindical, representación de los trabajadores, etc.) y sus correspondientes obligaciones para con los trabajadores (asistencia mínima a las reuniones de trabajo, información, convocatoria, etc.).

d. Definir la forma y requisitos para la designación del representante al comité, teniendo en cuenta el número de trabajadores de la empresa para lo primero y la naturaleza de su actividad para lo segundo. 